\title{
Pemulihan Serta Pencegahan Gejala Fisik dan Emosi Pada Lansia Melalui Senam Ergonomis Berbasis Spiritual
}

\author{
Shanti Wardaningsih ${ }^{1}$, Aneta Putri Arlindasari ${ }^{2}$, Gunadiah Annisa Septiningrum ${ }^{2}$, Firdasani Desma \\ Rosmala ${ }^{2}$, Sri Andini Widya Ningrum ${ }^{2}$, Sutan Kumala Pontas $\mathbf{N}^{2}$ \\ ${ }^{1}$ Staff Pengajar Prodi.Keperawatan FKIK Universitas Muhammadiyah Yogyakarta \\ ${ }^{2}$ Mahasiswa Universitas Muhammadiyah Yogyakarta \\ Email: shanti.wardaningsih@umy.ac.id
}

\begin{abstract}
Abstrak
Jumlah lansia di Indonesia yang tinggi, dapat mendatangkan dampak positif bagi negara bila produktifitas lansia tinggi. Namun demikian dapat mendatangan dampak negatif jika ketergantungan lansia tersebut tinggi. Ketergantungan tersebut disebabkan antara lain karena penurunan kondisi dan kemampuan fisik yang di alami oleh lansia. Angka ketergantungan lansia di Indonesia tersebut adalah 100 orang penduduk produktif terbebani oleh 14 orang Lanjut Usia (lansia). Pemerintah sudah memfasilitasi penanganan masalah kesehatan lansia melalui posyandu lansia, namun program tersebut masih belum optimal sehingga penting bagi lansia untuk dapat mencegah dan mengatasi masalah kesehatannya secara mandiri agar masalah kesehatan yang dikeluhkan dapat teratasi. Senam ergonomis berbasis spiritual memiliki tujuan dapat meningkatkan status kesehatan lansia dan meningkatkan pengetahuan maupun kemampuan lansia dalam mencegah dan mengatasi penyakit fisik dan emosi. Program penerapan senam ergonomis berbasis spiritual bagi lansia dilakukan di Dusun Godegan, Tamantirto, Kasihan Bantul. Kegiatan yang bekerjasama dengan PKK Dusun Godegan ini dilakukan melalui beberapa tahap yaitu perijinan, persiapan, pelaksanaan kegiatan, dan evaluasi. Program ini dilakukan selama 3 bulan, dan kegiatan dilakukan 2 minggu sekali. Program ini memiliki beberapa kegiatan yaitu Senam Ergonomis (senam derivasi gerakan shalat) dengan diiringi lantunan Asmaul Husna, pemeriksaan kesehatan gratis yang meliputi pemeriksaan gula darah, kolesterol, asam urat, tekanan darah, tinggi badan, dan berat badan, serta konsultasi kesehatan dan spiritual dengan fasilitator yang ahli dibidangnya. Jumlah peserta diantara $19-35$ orang/kegiatan. Ketercapaian kegiatan ini adalah terjadinya trend peningkatan stabilitas dari tekanan darah dan kadar gula setelah dilakukan senam ergonomis pada lansia sebanyak lima kali kegiatan. Selain itu, terbentuknya komunitas Senam Ergonomis Berbasis Spiritual, beserta pengurus yang mengelola kegiatan tersebut secara rutin, $C D$ tutorial dan buku panduan bagi kader Senam ergonomis berbasis spiritual. Senam ergonomis berbasis spiritual mampu meningkatkan pengetahuan dan kemampuan ketrampilan psikomotorik lansia dalam mencegah dan memulihkan gejala fisik maupun emosi melalui edukasi dan pemberian materi atau pendidikan kesehatan serta memfasilitasi lansia dalam penanganan masalah kesehatan sehingga tercapai peningkatan status kesehatan. Rekomendasi dari kegiatan ini bagi pemerintah adalah merevitalisasi dari fungsi posyandu dengan merekomendasikan aktifitas ini sebagai alternatif menyelesaikan masalah lansia. Bagi pengelola posyandu dan lansia yaitu melakukan secara rutin kegiatan senam ergonimis disamping seman lansia yang sudah rutin dilakukan.
\end{abstract}

Kata kunci: Lansia, Senam Ergonomis, Spiritual.

\begin{abstract}
The high number of elderly people in Indonesia can have a positive impact on the country if the productivity of the elderly is high. However, it can have a negative impact if the dependence of the elderly is high. This dependence is due to, among other things, a decrease in the condition and physical abilities experienced by the elderly. The dependency rate for the elderly in Indonesia is 100 productive population burdened by 14 elderly people (elderly). The government has facilitated the handling of elderly health problems through elderly posyandu, but the program is still not optimal so it is important for the elderly to be able to prevent and overcome their health problems independently so that the health problems they complain about can be resolved. Spiritual-based ergonomic exercise has the aim of improving the health status of the elderly
\end{abstract}


and increasing the knowledge and ability of the elderly in preventing and overcoming physical and emotional illness. The spiritual-based ergonomic exercise program for the elderly was carried out in Dusun Godegan, Tamantirto, Kasihan Bantul. This activity in collaboration with the Godegan Village PKK was carried out in several stages, namely licensing, preparation, implementation of activities, and evaluation. This program is carried out for 3 months, and activities are carried out every 2 weeks. This program has several activities, namely Ergonomic Gymnastics (gymnastics for the derivation of prayer movements) accompanied by the chanting of Asmaul Husna, free health checks which include checks for blood sugar, cholesterol, uric acid, blood pressure, height and weight, as well as health and spiritual consultations with facilitators who are experts in their fields. The number of participants is between 19 - 35 people / activity. The achievement of this activity is the trend of increasing the stability of blood pressure and sugar levels after doing five ergonomic exercises for the elderly. In addition, the formation of a spiritually based Ergonomic Gymnastics community, along with administrators who regularly manage these activities, tutorial CDs and guidebooks for spiritually-based ergonomic gymnastics cadres. Spiritual-based ergonomic exercise is able to increase the knowledge and psychomotor skills of the elderly in preventing and recovering physical and emotional symptoms through education and provision of materials or health education and facilitating the elderly in handling health problems so that an increase in health status can be achieved. The recommendation of this activity for the government is to revitalize the posyandu function by recommending this activity as an alternative to solving elderly problems. For posyandu managers and the elderly, they routinely carry out ergonomic exercise in addition to the routine elderly seminars.

Keywords: Elderly, Ergonomic Gymnastics, Spiritual.

\section{PENDAHULUAN}

Lanjut usia (lansia) merupakan kenyataan yang tidak dapat dihindari dari setiap individu. Hal ini merupakan tahap akhir siklus normal dari kehidupan setiap manusia. Berdasarkan pengelompokan usianya lansia dibagi menjadi : pralansia (usia 45-59 tahun), lansia (usia 60 tahun atau lebih), dan lansia risiko tinggi (usia 70 tahun atau lebih) (Depkes RI, 2003). Menurut Undang-Undang Republik Indonesia Nomor 13 tahun 1998 tentang Kesejahteraan Lanjut Usia, definisi lansia adalah seseorang yang telah mencapai usia 60 tahun ke atas. Sedangkan menurut World Health Organisation (WHO) lanjut usia meliputi; usia pertengahan (middle age) yaitu kelompok usia 45 - 59 tahun, usia lanjut (elderly), kelompok usia 60 - 70 tahun, dan usia tua (old) yaitu kelompok usia antara 75 - 90 tahun, serta usia sangat tua (very old), kelompok usia diatas 90 tahun (Sutikno, 2011). Indonesia merupakan salah satu negara dengan struktur tua karena populasi lansia yang tinggi, walaupun jumlah penduduk kurang dari 15 tahun lebih besar dari penduduk lansia (di atas 60 tahun), tetapi pada tahun 2040 baik global, Asia dan Indonesia diprediksikan jumlah penduduk lansianya sudah lebih besar dari jumlah penduduk kurang 15 tahun. Hal ini sejalan dengan meningkatnya derajat kesehatan dan kesejahteraan penduduk yang akan berpengaruh pada peningkatan Usia Harapan Hidup (UHH) di Indonesia. Laporan Badan Pusat Statistik (BPS), pada tahun 2000 UHH di Indonesia adalah 64,5 tahun (dengan persentase populasi lansia 7,18\%). Angka ini meningkat menjadi 69,43 tahun pada tahun 2010 (dengan persentase populasi lansia 7,56\%) dan pada tahun 2011 menjadi 69,65 tahun (dengan persentase populasi lansia 7,58\%). Kemudian berdasarkan Susenas tahun 2012, BPS RI, jika dilihat sebaran penduduk lansia menurut provinsi, persentase penduduk lansia paling tinggi ada di Provinsi DI. Yogyakarta (13,04\%). Meskipun secara umum hal tersebut terjadi karena peningkatan derajat kesehatan, namun tingginya angka lansia tetap berpengaruh terhadap tingginya angka penyakit degeneratif khususnya di Daerah Istimewa Yogyakarta yang memiliki populasi lansia tinggi.

Dengan jumlah lansia yang banyak tersebut, dimungkinkan akan menimbulkan dampak positif jika dikelola dengan baik, akan tetapi bisa menimbulkan dampak negatif jika lansia mengalami kondisi-kondisi yang telah disebutkan sebelumnya. Masalah-masalah diatas menyebabkan angka ketergantungan lansia yang tinggi yaitu 13,28 artinya setiap 100 
penduduk dewasa produktif dibebani oleh kurang lebih 14 orang lansia (Kementrian Kesehatan $\mathrm{RI}, 2017 \mathrm{~b})$. Pemerintah telah melakukan upaya pemeliharaan kesehatan bagi lanjut usia ditujukan untuk menjaga agar para lanjut usia tetap sehat, mandiri, aktif dan produktif secara sosial dan ekonomi. Dalam mewujudkan hal itu, pemerintah mempunyai kewajiban untuk menjamin ketersediaan fasilitas pelayanan kesehatan serta menyediakan fasilitas dalam pengembangan kelompok lanjut usia, antara lain melalui Poksila (kelompok lansia) di Posyandu.

Pemerintah telah membuat kebijakan maupun program yang mendukung untuk terciptanya lansia dengan derajat kesehatan tinggi, seperti program kartu menuju sehat lansia dan posyandu lansia. Namun hal tersebut masih belum efektif karena belum dapat menangani angka sakit lansia secara keseluruhan hingga ke desa. Laporan BPS (2012), angka kesakitan lansia tahun 2008 sampai 2012 di daerah perkotaan cenderung lebih rendah dibandingkan daerah pedesaan, hal ini diartikan bahwa derajat kesehatan lansia yang tinggal di daerah perkotaan relatif lebih baik di banding pedesaan. Salah satu bentuk aktifitas yang dapat dilakukan untuk mengatasi penyakit kronis (hipertensi, diabetes dan lain - lain), adalah dengan melakukan aktifitas fisik. Senam yang diinspirasi dari gerakan sholat menjadi dasar dari setiap gerakan sholat. Senam ergonomis didasarkan pada kepercayaan bahwa tubuh manusia memiliki sifat dan mekanisme yang berlaku dalam proses - proses kedalam (autoregulasi), maupun keluar (adaptasi) yang merupakan bawaan manusia semenjak lahir. Gerakan Senam ergonomis dilakukan sesuai dengan susunan dan fungsi fisiologi tubuh. Senam ergonomis mempunyai fungsi autoregulasi karena sholat mengandung serangkaian gerakan hati, lisan dan anggota badan (Sagiran, 2012). Dengan demikian, gerakan senam ergonomis tersebut membiasakan tubuh akan bekerja dengan fisiologis, sehingga mengembalikan metabolisme tubuh orang yang melakukanya. Gerakan - gerakan yang dilakukan, mengantarkan tubuh untuk memperbaiki fungsi - fungsinya.

Berdasarkan permasalahan-permasalahan diatas maka menurut pemikiran pelaksana perlu dibuat kegiatan yang dapat membantu lansia kususnya lansia yang tinggal di desa untuk dapat mencegah dan mengatasi penyakitnya secara mandiri. Program kegiatan ini disebut Senam Ergonomis Berbasis Spiritual untuk megejala Fisik dan Emosi pada Lansia di Godegan Rt 10 DK VII Brajan, Tamantirto, Kasihan, Bantul. Berdasarkan survey pendahuluan pada lansia dukuh Godegan RT 10 pada tanggal 8 Okober 2015 didapatkan 54,54\% lansia merasa sakit dengan keluhan nyeri punggung $40,90 \%$, nyeri sendi $40,90 \%$, hipertensi $31,81 \%$, kolesterol $31,81 \%$, asam urat $18,18 \%$, diabetes mellitus dan vertigo $9,09 \%$, dan keluhan-keluhan lain sebanyak 27,27\%. Dari segi psikis 31,81\% lansia mengatakan mudah marah, dan 31,80\% mengeluh mudah stress jika memiliki masalah. Kemudian 36,36\% dari mereka juga sudah tidak bekerja. Hal tersebut juga memicu timbulnya stress maupun depresi karena perubahan aktifitas. Dari proses anamnesis atau wawancara yang dilakukan juga diketahui bahwa sebagian besar lansia mengalami gangguan tidur.

Program pemerintah dalam mensejahterakan lansia di Godegan RT 10 yang berjalan rutin diantaranya adalah posyandu lansia yang diadakan setiap tanggal 8. Namun dari pengamatan pelaksana ketika mendatangi kegiatan tersebut, posyandu lansia di Godegan RT10 kurang efektif karena dalam kegiatan tersebut pemeriksaan yang dilakukan terbatas hanya pada pemeriksaan tekanan darah, berat badan, dan konsultasi kesehatan. Hal tersebut sejalan dengan hasil kuisioner bahwa 27,27\% lansia Godegan RT 10 mengatakan posyandu lansia dan kegiatan berbasis kesehatan disana kurang efektif dan kurang memuaskan dalam membantu lansia mengatasi masalah kesehatannya baik dari segi preventif maupun kuratif.

Tujuan diadakannya program Senam Ergonomis Berbasis Spiritual ini adalah : 
1. Meningkatkan pengetahuan lansia mengenai cara mencegah dan memulihkan penyakit fisik maupun emosi sehingga tercapai derajat kesehatan yang baik.

2. Meningkatkan kemampuan lansia dalam mencegah dan memulihkan penyakit fisik dan emosi.

Luaran yang diharapkan dari pengabdian ini adalah terbentuknya komunitas Senam Ergonomis Berbasis Spiritual sebagai inovasi untuk penanganan non farmakologi bagi lansia yang memiliki penyakit fisik maupun emosi dengan berdasar pada nilai-nilai keislaman dalam rangka meningkatkan derajat kesehatan pada lansia. Tidak hanya itu, Senam Ergonomis Berbasis Spiritual dapat berkelanjutan dan dikelola oleh kader-kader terbentuk yang dapat bekerjasama dengan Posyandu Lansia untuk dapat dikembangkan serta dapat diikuti oleh berbagai elemen masyarakat.

Dalam hal ini sangatlah penting bagi para lansia untuk membentuk suatu wadah yang akan mereka gunakan untuk memperoleh informasi, saling berbagi pengalaman dan ilmu, serta mendapatkan bimbingan maupun motivasi agar dapat menerapkan budaya hidup sehat. Tak hanya itu saja, melalui Senam Ergonomis Berbasis Spiritual lansia akan mendapatkan bekal ilmu tentang religiusitas yang diharapkan dapat mengatasi masalah-masalah yang berkaitan dengan psikis maupun emosi dengan mengingat Tuhan.

\section{METODE PELAKSANAAN}

Program Senam Ergonomis Berbasis Spiritual ini melalui beberapa tahap yaiu tahap persiapan, pelaksanaan, dan evaluasi.

Perizinan kegiatan Senam Ergonomis Berbasis Spiritual kepada aparat desa setempat, yaitu Ketua RT 10 Godegan, Kader posyandu Lanjut Usia (Lansia) setempat, dan pengurus masjid Al-Amin terkait perizinan tempat kegiatan. Peserta yang terlibat dalam kegiatan ini adalah para anggota Posyandu Lansia yang terdiri dari Lansia dan Kader Kesehatan Lansia.

1. Persiapan kegiatan Senam Ergonomis Berbasis Spiritual yang dilakukan antara lain:

a. Persiapan peserta, yaitu dengan mengundang lansia di Godegan RT 10.

b. Persiapan tempat, yaitu dengan mengonfirmasi perizinan Masjid Al-Amin sebagai tempat yang akan digunakan, dan menyiapkan lokasi sesuai dengan kebutuhan.

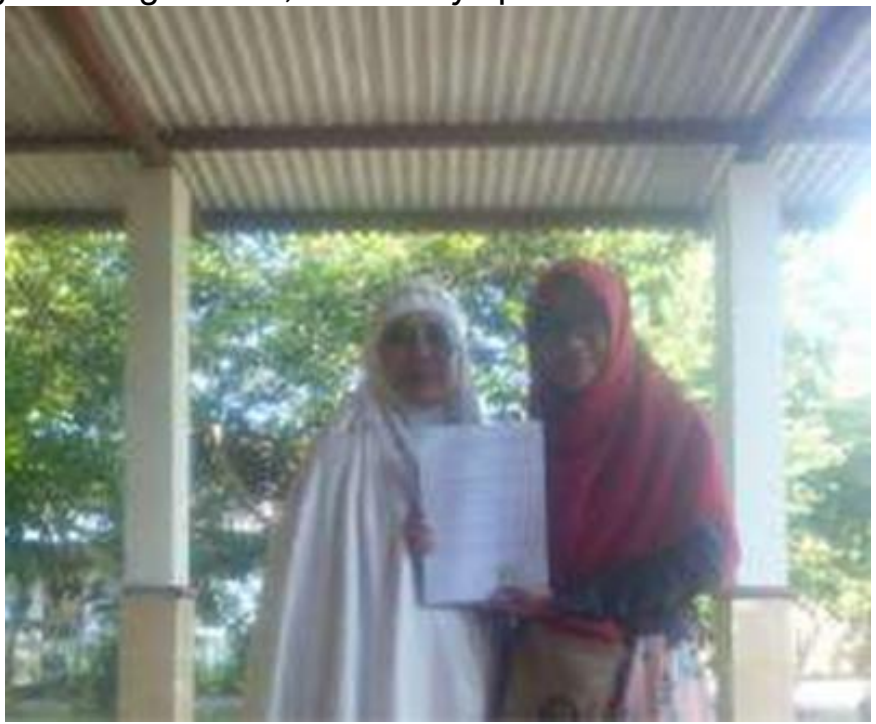

Gambar 1. Penadatangan Kerjasama 
c. Persiapan media, dilakukan dengan menyiapkan media audio baik musik instrumental untuk gerakan pemanasan maupun musik lantunan asmaul husna sebagai music relaksan pada Senam Ergonomis Berbasis Spiritual.

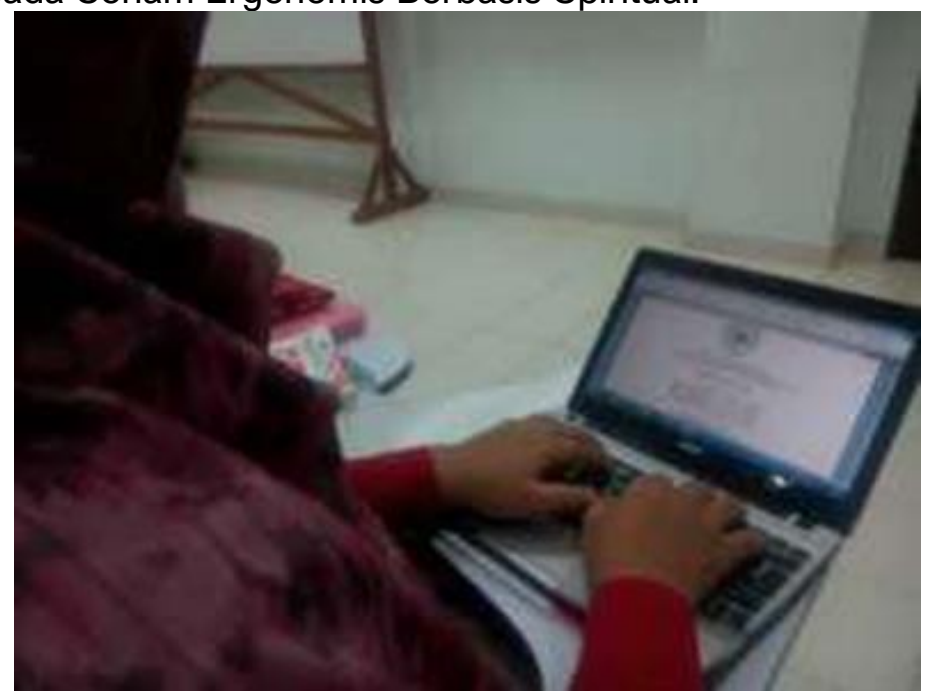

Gambar 1 Persiapan Pembuatan Media

d. Persiapan Fasilitator ataupun pemateri yang professional baik dalam bidang spiritual mapun dalam kesehatan khususnya Holistic Nursing Care.

2. Pelaksanaan Kegiatan

a. Kegiatan Senam Ergonomis Berbasis Spiritual.

Pelaksanaan program Senam Ergonomis Berbasis Spiritual adalah dimulai dari pembentukan "peer group". "Peer group" yang dibentuk adalah kelompok yang dibagi berdasarkan jenis kelamin. Hal tersebut bertujuan untuk meminimalisir ketidaknyamanan saat senam berlangsung. Kegiatan Senam Ergonomis Berbasis Spiritual dilaksanakan selama 3 bulan setiap 2 minggu sekali dengan durasi 2 jam per pertemuan. Rangkaian kegiatan yang dilakukan setiap pertemuan adalah Senam Ergonomis (senam dengan derivasi gerakan shalat), yang merupakan salah satu metode dalam pencegahan dan pemulihan penyakit fisik dan emosi pada lansia. Senam tersebut diinovasi dengan penambahan iringan lantunan Asma'ul Husna dan peserta senam diminta mengikuti lantunan Asma'ul Husna yang memiliki manfaat menambah kedekatan dengan Tuhan, meningkatkan ketenangan dan kedamaian batin serta mampu memaknai kehidupan sebagai hal yang harus dinikmati dan disyukuri.

Kegiatan dilanjutkan dengan pemeriksaan kesehatan gratis berupa pemeriksaan tekanan darah post senam, berat badan, tinggi badan, gula darah, kolesterol, dan asam urat. Dalam setiap kegiatan Senam Ergonomis Berbasis Spiritual akan dihadirkan fasilitator yang profesional baik dibidang kesehatan (Holistic Nursing Care, Gerontik) ataupun spiritual sebagai konsultan. Dalam kegiatan Senam Ergonomis Berbasis Spiritual juga diselingi dengan pemberian materi tentang kesehatan dan pendidikan agama.

Selain itu untuk keberlangsungan kegiatan, maka dilakukan pengkaderan (training for trainer), yaitu mengajarkan kepada ibu - ibu pengurus posyandu 
lansia tentang Senam Ergonomis. Pelaksanaan Pengkaderan dilakukan hanya sekali. Tujuannya adalah untuk menciptakan pengurus Senam Ergonomis Berbasis Spiritual secara mandiri oleh masyarakat sehingga program dapat terus terlaksana secara keberlanjutan. Kader yang dipersiapkan terdiri atas kader posyandu lansia yang sudah ada maupun dari Departemen Sosial Kemasyarakatan Himpunan Mahasiswa IImu Keperawatan PSIK FKIK UMY. Agenda pengkaderan terdiri atas pemaparan program dan rencana keberlanjutan serta pelatihan Senam Ergonomis Berbasis Spiritual.

b. Evaluasi kegiatan

Evaluasi Senam Ergonomis Berbasis Spiritual dilakukan dengan mengamati perubahan pengetahuan dan kemampuan lansia dengan cara observasi dan survey serta evaluasi perubahan tingkat kesehatan dengan membandingkan hasil pemeriksaan kesehatan pada rekam medis dan wawancara singkat.

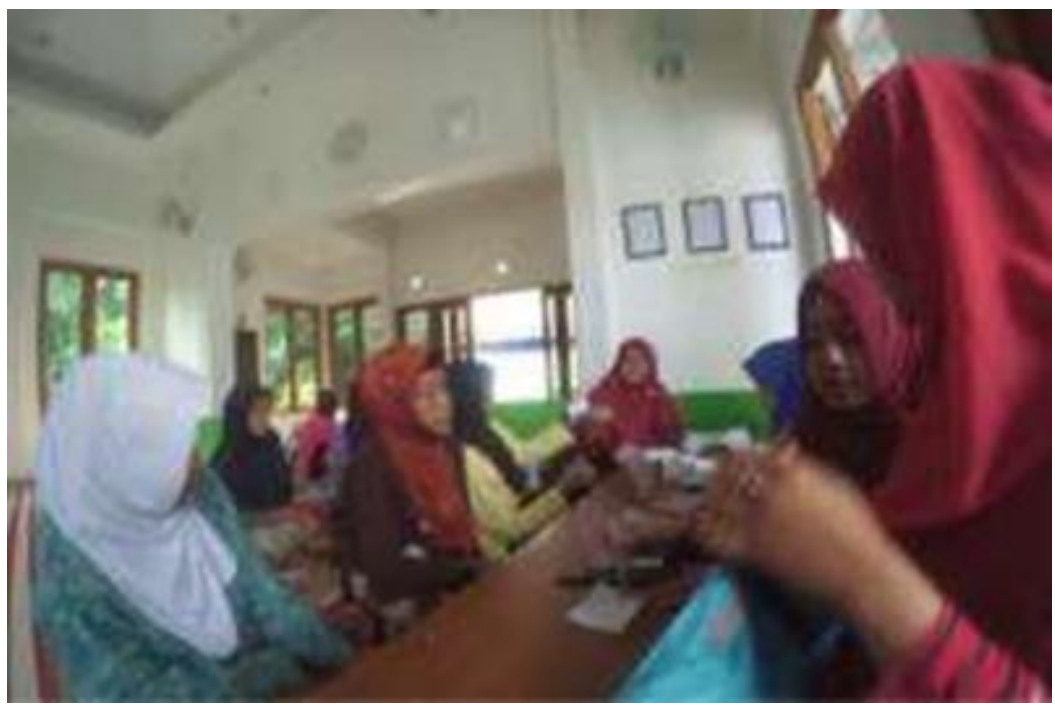

Gambar 2. Pemerikasaan Kesehatan

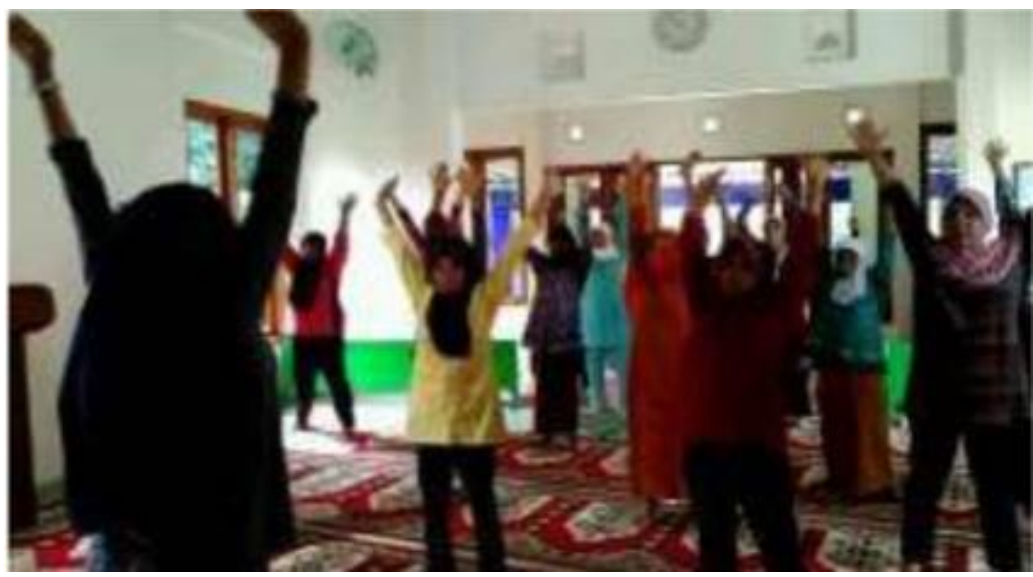

Gambar 3. Pelaksanaan Senam Ergonomis berbasis Spiritual 


\section{HASIL DAN PEMBAHASAN}

Kegiatan Senam Ergonomis Berbasis Spiritual ini sudah dilakukan selama tiga bulan sejak bulan Maret 2016 dengan pelaksanaan kegiatan Senam Ergonomis Berbasis Spiritual terdiri dari 4 tahap prosedur pelaksanaan kegiatan, dimulai dari perizinan, pesiapan, pelaksanaan kegiatan dan evaluasi. Hasil dari kegiatan Senam Ergonomis ini menunjukkan adanya tren kondisi tekanan darah dan kadar glukosa dari lansia yang semakin stabil.

Berdasarkan hasil wawancara pada pertemuan ke-5 kegiatan pada peserta yang sudah mengikuti kegiatan lebih dari $1 \mathrm{kali}, 45 \%$ lansia mengatakan gangguan tidur berkurang, 95\% mengatakan nyeri punggung berkurang, dan 40\% mengatakan menjadi lebih tenang setelah senam (Tabel 1). Hal tersebut sesuai dengan penelitian dari Perdana (2014) yang menyatakan bahwa senam ergonomis low impact mampu menurunkan tekanan darah. Senam ergonomis yang dilakukan pada lansia, diketahui akan meningkatkan aliran darah, sehingga mencegah terjadinya arteloskelerosis. Jika dilaksanakan secara terus menerus, maka akan efektif menstabilkan tekanan darah pada lansia. Selain itu, secara psikologis akan berbengaruh juga untuk mencukupi waktu istirahat dari lansia, hal ini dinyatakan oleh Sutantri (2014) yang membuktikan bahwa efek dari senam ergonomis dapat memperbaik kualitas tidur dari lansia.

Tabel.1 Rekapitulasi Status Kesehatan Peserta Kegiatan Senam Ergonomis Berbasis Spiritual

\begin{tabular}{|c|c|c|c|c|c|c|c|}
\hline \multirow{2}{*}{$\begin{array}{c}\text { Pertemuan } \\
\text { ke- }\end{array}$} & \multirow{2}{*}{$\begin{array}{c}\text { Jumlah } \\
\text { kehadiran }\end{array}$} & Hipotensi & Normal & Hipertensi & Hipoglikemi & Normal & $\begin{array}{c}\text { Hiperglike } \\
\text { mi }\end{array}$ \\
\cline { 3 - 8 } & 19 Peserta & 1 & 11 & 7 & 1 & 17 & 1 \\
\hline 1 & 29 Peserta & 0 & 22 & 7 & 2 & 23 & 2 \\
\hline 2 & 35 Peserta & 1 & 28 & 6 & 3 & 27 & 5 \\
\hline 3 & 24 Peserta & 0 & 22 & 2 & 4 & 18 & 2 \\
\hline 4 & 20 Peserta & 0 & 18 & 2 & 1 & 18 & 1 \\
\hline 5 & & & & & & & \\
\hline
\end{tabular}

Gerakan senam ergonomis terdiri dari lima gerakan utama, yang masing-masing mempunyai efek pada fungsi tubuh manusia. Akan dijelaskan beberapa contoh fungsi dari gerakan senam yang dilakukan dan fungsinya bagi tubuh. Gerakan pertama mempunyai fungsi untuk membawa tubuh pada ke kondisi rileks. Gerakan berdiri dengan sempurna, dengan kendali otak, menjadikan seluruh syaraf menjadi satu titik. Pada saat gerakan ini, pikiran dikendalikan oleh kesadaran akal yang mengantarkan kondisi sehat dan bugar, tubuh dibebaskan dari beban pikiran akan pekerjaan, beban tubuh ditumpukan dengan pembagian berat pada kedua kaki dengan sama. Pada posisi ini telapak kaki menekan seluruh titik saraf ditelapak kaki termasuk titik syaraf yang mempengaruhi kerja pankreas dan hal ini bermanfaat bagi kesehatan tubuh. Posisi ini juga akan membentuk punggung menjadi lurus sehingga akan memperbaiki bentuk tubuh, jantung dan paru - paru bekerja normal, serta memperbaiki postur yang salah akibat aktivitas sehari - hari (Sagiran, 2012).

Gerakan kedua berfungsi untuk meningkatkan input oksigen ke dalam tubuh, serta meningkatkan metabolisme dan refleksi fungsi organ dalam. Saat lengan terangkat ke atas, tulang - tulang rusuk saling meregang ikut terangkat bagian depannya sehingga rongga dada akan berada dalam ukuran yang paling lebar, tekanan udara didalam menjadi negatif sehingga udara segar bisa masuk rongga dada. Pada saat tangan bergerak kebelakang serta turun, terjadi proses sebaliknya sehingga udara bisa keluar. Putaran lengan pada bahu menyebabkan stimulus untuk 
mengoptimalkan fungsi cabang besar saraf dibahu (pleksus brakhialis) dalam merangsang saraf pada organ paru, jantung, liver, ginjal, lambung dan usus sehingga metabolisme tubuh optimal. Sedangkan saat kedua kaki melakukan jinjit dapat meningkatkan stimulus sensor - sensor saraf yang merupakan refleksi fungsi organ dalam dan penumpukan glukosa darah pada kaki pasien DM akan meningkatkan sirkulasi darah pada kaki (Sagiran, 2012).

Melihat hasil dari lima kali pelaksanaan senam ergonomis berbasis spiritual ini, maka dapat diasumsikan bahwa senam ergonomis ini sangat direkomendasikan untuk lansia yang telah mempunyai penurunan fungsi tubuh sangat bermanfaat.

\section{Potensi Keberlanjutan}

1. Terjalinnya kerjasama dengan posyandu lansia Godegan dan Himpunan Mahasiswa IImu Keperawatan (HIMIKA) FKIK UMY sehingga kegiatan dapat terus dilaksanakan secara berkelanjutan bersama posyandu lansia yang bekerjasama dengan HIMIKA FKIK UMY khususnya melalui departemen sosial kemasyarakatannya.

2. Keberlanjutan hasil dari kegiatan pengabdian masyarakat ini adalah berupa CD tutorial Senam Ergonomis Berbasis Spiritual (Senam Ergonomis Berbasis Spiritual) yang berpeluang memperoleh hak cipta dan selanjutnya dapat berpotensi menjadi usaha kewirausahaan yang mampu memberikan profit besar bagi kemajuan komunitas Senam Ergonomis Berbasis Spiritual.

3. Senam Ergonomis Berbasis Spiritual dapat berlanjut untuk diadopsi di seluruh elemen masyarakat Indonesia agar seluruh masyarakat khususnya lansia dapat secara mandiri meningkatkan derajat kesehatannya melalui Senam Ergonomis Berbasis Spiritual.

\section{SIMPULAN}

Berdasarkan hasil pelaksanaan kegiatan Senam Ergonomis Berbasis Spiritual untuk Pemulihan dan Pencegahan Gejala Fisik Dan Emosi pada Lansia di Godegan, dapat disimpulkan bahwa:

1. Senam Ergonomis Berbasis Spiritual mampu meningkatkan pengetahuan dan kemampuan lansia dalam mencegah dan memulihkan penyakit fisik maupun emosi melalui aspek edukasi dengan cara pemberian materi atau pendidikan kesehatan.

2. Senam Ergonomis Berbasis Spiritual memfasilitasi lansia dalam penanganan masalah kesehatan baik penyakit fisik maupun emosi dan tercapai peningkatan status kesehatan.

\section{UCAPAN TERIMA KASIH}

Ucapan terima kasih kepada Direktorat Jenderal Pendidikan Tinggi

Ucapan terima kasih LP3M UMY

Ucapan terima kasih juga kelompok Pekan Kreatifitas Mahasiswa Wiwit, Gunad, Aned, Firda dan semua pihak yang tidak dapat saya sebutkan satu persatu

\section{DAFTAR PUSTAKA}

Dinas Kesehatan DIY. 2012. Profil Kesehatan Penduduk Indonesia. Departemen Kesehatan Provinsi DIY

Kementerian Kesehatan RI. 2013. Buletin Jendela Data dan Informasi Kesehatan. Diakses pada 30 September 2015.

Kementerian Kesehatan RI. 2012. Situasi dan Analisis Lanjut Usia. Diakses pada 30 September 2015. 
Kementerian Kesehatan RI. 2017. Pusat Data dan Informasi : Analisis Lansia di Indonesia. Diakses September 2017.

Peraturan Menteri Kesehatan Republik Indonesia Nomor 25 Tahun 2016. Rencana Aksi Nasional Kesehatan Lanjut Usia Tahun 2016-2019.

Sagiran.. 2007. Mukzizat Gerakan Shalat. Jakarta : Qultum Media

Sagiran. 2014. Sehat Gaya Rasul: Warisan Nabi yang Terlupakan. Jakarta : Qultum Media

Sutantri E, Suratini. 2014. Pengaruh Senam Ergonomis terhadap Perubahan Kualitas Tidur pada Lansia di Padukuhan Bonosoro Bumirejo Lendah Kulon Progo, Yogyakarta, Skripsi

Novia, Putri Ningsih. 2015. Pengaruh Senam Ergonomis Terhadap Tekanan Darah Lansia Hipertensi Di Posyandu Lansia Ayah Bunda Wilayah Kerja Puskesmas Andalas Padang, Sumatra Barat: Skripsi

Wratsongko, Madyo. 2006.Shalat Jadi Obat. Jakarta : Elex Media Komputindo

Wratsongko, Madyo. 2006. Pedoman Sehat Tanpa Obat. Jakarta : Elex Media Komputindo 